\title{
The Relationship between National Culture and Organisational Culture: The Case of Iranian Private Sector Organisations
}

\author{
Alireza Nazarian, Zahir Irani, and Maged Ali
}

\begin{abstract}
The purpose of this paper is to investigate the relationship between National Culture (NC) and Organisational Culture (OC) in the context of private sector organisations in Iran. This paper outlines some frameworks of NC and OC then looks at some relevant specific cultural perceptions on the part of Iranian managers. The NC and $\mathrm{OC}$ of several organizations in Iran were investigated using survey methodology. Questionnaires were distributed through organisations either by email or hard copy. 221 questionnaires were returned. To investigate $\mathrm{NC}$ the researcher used the Dorfman and Howell questionnaire. Furthermore, to study $\mathrm{OC}$ the researcher used the Organisational Culture Assessment Instrument (OCAI) which is based on the CVF framework. Regression analysis of the results showed that most of the dimensions of $\mathrm{NC}$ have insignificant relationship with $\mathrm{OC}$ except for the relationship of NC with clan culture. However, the correlations analyses provide some additional support for the association between these two constructs. This paper concludes that company size can serve as an important and significant moderator of the association between $\mathrm{NC}$ and $\mathrm{OC}$ within these data. Moreover, the results indicate that both education and position serve as significant controls of the association between NC and OC. It is recommended that researchers should consider the industrial cultural effect as a factor that would help for a better understanding of the relationship between $\mathrm{NC}$ and $\mathrm{OC}$ phenomena.
\end{abstract}

Index Terms-National culture, organisational culture, CVF, private sector, Iran.

\section{INTRODUCTION}

Differences in culture have considerable impact on both the personal and corporate spheres of society. Organisational culture affects organizations in various contexts and it has been recognized as one of the most influential factors when considering organizational performance [1]. Sagiv and Schwartz [2] also concluded in their research that company values are more important than those of market forces (for example: Wal-Mart and U.S. South-west-Airlines etc.). This increased importance of culture for researchers in organisational studies has become a source in the development of different theories, frameworks and models aimed at explaining organizational culture. Likewise, NC is another important consideration because of its deeply rooted linkage with the values, entrenched in our everyday life. Cultural values are part of our daily life and we start learning these values in our childhood. Similarly, our communication, behaviour and actions are shaped by these adopted cultural

Manuscript received November 5, 2012; revised January 10, 2013.

Alireza Nazarian is with University of Brunel (e-mail: alireza.nazarian@brunel.ac.uk). values. Therefore, it is appropriate to assert that national values have an impact on organizational culture as well. This premise is suggested by Hofstede, he states that 'behaviour at work is a continuation of behaviour learned earlier' [3]. Keeping in mind this relationship, the purpose of this paper is to investigate the relationship between $\mathrm{NC}$ and organizational culture specifically in the private sector of Iran.

\section{LITERATURE REVIEW}

Culture is a very difficult word to define although it is a familiar word for everybody. Williams [4] admits that 'culture is one of the two or three most complicated words in the English language'. Geertz suggests that culture is 'an historically transmitted pattern of meanings embodied in symbols, a system of inherited conceptions expressed in symbolic form by means of which men communicate, perpetuate, and develop their knowledge about attitudes toward life' [5]. Hofstede defines culture as ' ... the collective programming of the mind which distinguishes the members of one group or category of people from another' [6]. Furthermore, Hofstede argues that the core element of any culture is its values. He further defines values as "broad tendencies to prefer certain states of affairs over others" [7]

\section{A. Dimensions of National Culture}

Hofstede introduced four dimensions of NC and he later introduced a fifth:

\begin{tabular}{|l|l|}
\hline \multicolumn{2}{|c|}{ TABLE I: HOFSTEDE'S NC DIMENSIONS } \\
\hline Power distance: & $\begin{array}{l}\text { Measures the degree to which the less } \\
\text { powerful members of society accept } \\
\text { and expect that power is distributed } \\
\text { unequally. }\end{array}$ \\
\hline Uncertainty Avoidance: & $\begin{array}{l}\text { Measures a society's tolerance for } \\
\text { uncertainty and ambiguity; the extent } \\
\text { to which the culture likes to control } \\
\text { the future }\end{array}$ \\
\hline $\begin{array}{l}\text { Masculinity } \\
\text { Femininity: }\end{array}$ & $\begin{array}{l}\text { Measures the distribution of roles } \\
\text { between the genders. }\end{array}$ \\
\hline Collectivism & $\begin{array}{l}\text { Measures the extent to which people } \\
\text { expect to look after him/herself and } \\
\text { immediate family compared to the } \\
\text { degree of support expected from } \\
\text { social institutions }\end{array}$ \\
\hline $\begin{array}{l}\text { Short-term and long-term } \\
\text { Orientation: }\end{array}$ & $\begin{array}{l}\text { Measures the degree to which society } \\
\text { embraces long term commitment to } \\
\text { traditional as opposed to forward } \\
\text { thinking values. }\end{array}$ \\
\hline
\end{tabular}

\section{B. Organizational Culture}

Organisational culture is a relatively new term which first appeared in organisational studies in the 1970s. At the beginning 'culture' was used as a substitute for climate [8]. 
However, since the 1980s many scholars such as [9] have questioned the relationship between the two and instead believe that the two terms should be kept separate. Morgan [10] defines OC as the pattern of development reflected in society's system of knowledge, ideologies, values, laws, and day-to-day rituals. Similarly [9] defines OC as the shared values, beliefs, norms, expectations and assumptions which function like a glue holding employees and organisations' systems together and stimulate employees' performance and commitment [11]-[14]. His view of culture is based on culture deriving from an underlying pattern of assumptions that people in any organisation share as a result of the common experiences they all have. Also, OC has been defined as shared perceptions of organisational work practice within organisational units [15], which provide a guideline for the organisation's business mission and goals [16].

\section{Culture Studies Specific to Iran Context}

Hofstede categorised Iran alongside Turkey and Greece in the Near Eastern cluster. His results show that Iran scored very highly on the 'collectivistic' dimension of NC, implying that Iranians co-operate well in a team. Considering that Iran has been greatly influenced by Islamic principles, for the last three decades, which place a strong emphasis on justice, harmony and generosity in the workplace, this result might be expected. On the other hand, [17] argues that Iran's culture could be better viewed as 'individualistic' rather than 'collectivistic'. She further argues that team co-operation and group work do not generally fit well with Iranian culture. This result has been supported by [18]-[21]. Namazie [22] used Hofstede's model to examine Iran and compared it with Hofstede's findings. Namazie's findings indicate that Iranian national culture has been becoming closer to western culture on almost all dimensions, apart from collectivism and long term orientation. That could indicate that the revolution and the Iran-Iraq war have had a big influence on changing some aspects of Iranian national culture and this change is a part of what, Iranian leaders have termed "Cultural Revolution" [23].

\section{Organisational Culture and Iranian Organisations}

There have been some studies conducted in Iran of organizational culture which have used many organizations from different sectors such as service management, education, industry, government organizations and high-tech industrial organizations [24]-[26]. By considering the literature related to organizational culture [24] suggest the ideal model for organizational culture management which includes components empowered by Islamic values such as honesty, trust in God, loyalty, justice counseling and guidance from top management. However, what he found was far from his expectation and came as a shock to many people. He discovered that there is a huge gap between the current OC and the ideal cultural model in government organizations. Furthermore, he identified that job satisfaction in the organizations which practice good ideas from the ideal cultural model is very high.

Around two years after the [24] study, [25] looked at the effect of OC on job satisfaction in an Iranian auto company. $\mathrm{He}$ found that there is a positive relationship between the OC model used in that organisation and job satisfaction. His findings have been supported by other studies based on OC and job satisfaction such as [27] study on military organisation and [28] study on academic staff at Tehran University. However, in another study conducted by [29] on staff of physical education offices of Mazandaran province they found no relationship between OC and components of organisational effectiveness (organizational commitment, work motivation, the amount of negative resistance against change and improving quality).

Hosseini [30] used Hofstede's model of cross national study to investigate $\mathrm{OC}$ of seven Iranian companies. She found that only the measure of power distance was the same as in Hofstede's findings and that the other dimensions were totally. In another study [31] studied a selection of managers in public sector organisations based in Ilam province in Iran in terms of management style and OC. His findings support the general argument that $\mathrm{OC}$ has an effect on the management style selection. In a more recent study of the effect of leadership style and OC on effectiveness in sports organisations in Iran, [32] argue that the results of their study, based on structural equation model (SEM), show that transformational leadership has a significant positive influence on effectiveness and on organizational culture. On the other hand, their results show that transactional leadership has a direct and significant negative influence on organizational effectiveness and has an indirect and significant positive influence on organizational culture. Furthermore, in another study on OC and organisational effectiveness [26] find that although consistency and mission dimensions of Denison's cultural model have crucial impact on organizational culture, only mission dimension has a significant relationship with culture. Furthermore, they conclude that as a result of significant differences in the cultural dimensions in the 4 companies under their study they were not able to find a unique pattern to generalise the results expect for mission dimensions. Based on this literature review, the current study explores the relationship between $\mathrm{OC}$ and NC by hypothesizing the following statement for testing:

TABLE II: HYPOTHESES

\begin{tabular}{|l|l|}
\hline Hypothesis-1: & $\begin{array}{l}\text { There is a positive relationship between dimensions of } \\
\text { NC and Clan Culture }\end{array}$ \\
\hline Hypothesis-2: & $\begin{array}{l}\text { There is a positive relationship between dimensions of } \\
\text { NC and Adhocracy Culture }\end{array}$ \\
\hline Hypothesis-3: & $\begin{array}{l}\text { There is a positive relationship between dimensions of } \\
\text { NC and Hierarchy Culture }\end{array}$ \\
\hline Hypothesis-4: & $\begin{array}{l}\text { There is a positive relationship between dimensions of } \\
\text { NC and Market Culture }\end{array}$ \\
\hline Hypothesis-5: & $\begin{array}{l}\text { Company size serves as a significant moderator of the } \\
\text { association between NC and OC }\end{array}$ \\
\hline Hypothesis-6: & $\begin{array}{l}\text { The controls of education and position will serve as } \\
\text { substantial control measures with regard to the } \\
\text { association between NC and OC. }\end{array}$ \\
\hline
\end{tabular}

\section{RESEARCh METhodology}

The research methodology section is divided into two sections. The first section highlights the sampling and data collection procedure and the second section illustrates instrumentation. 
Convenience sampling was employed to collect data from managers working in small and medium organizations in Iran. Due to various operational difficulties, researchers had to use convenience sampling method. Although convenience sampling may reduce the representativeness of the sample, it can be justified when there is limited access to resources [33]. While in the case of Iran, rules and regulations for conducting research and collecting information from different organizations in Iran is very tight and becomes even more difficult when it comes to some sensitive issues such as culture.

\section{A. Instrumentation}

The researcher adopted the scale from Dorfman and Howell's work on national culture and the CVF work of [1] on OC. Information related to four dimensions of $\mathrm{NC}$ were extracted from a questionnaire designed by [34] having 22 questions for managers and senior managers in each organisation. Additionally an OC section, which comprises 24 questions, was adopted directly from the OC Assessment Instrument (OCAI). The OCAI has been used in extensive studies from the Far and Middle East to North America. The OCAI asks respondents to answer six questions based on six dimensions, thought by Cameron and Quinn to be critical and important in gaining an understanding of OC. In order to ensure the researcher authenticity, a covering letter from the researchers together with a supporting letter from Brunel University and a stamped envelope was attached to each questionnaire. Moreover, in the case of Iran, the researcher had to seek permission from Ministry of Education.

\section{RESULTS}

\section{A. Descriptive Statistics}

The descriptive statistics for data was presented in table-4. Results show that percentage of male participants was 47.6, while the percentage of female participants was 52.6. Most of the respondents were above $45(52.4 \%)$. The percentage of respondents with having post graduate as their education level is 53.8 , followed by undergraduate $(39.1 \%)$. There were few respondents with $\mathrm{PhD}$ as their qualification $(6.8 \%)$. The participation of middle and senior managers was high, while the percentage of chief executives was only 7.1.

\section{B. Reliability of the Constructs}

Results shows that all the dimensions of NC were highly reliable and their value were above 0.6 , while the overall reliability of $\mathrm{NC}$ is 0.932 . The dimension of organizational culture values ranges from 0.6 to 0.9 , while the reliability coefficient for organizational culture is 0.940 .

\section{Hypothesis Testing}

In order to test the hypothesis, regression analysis was employed. For the hypothesis 1 results show that UAI $(B=-0.238, P<0.05)$, REVIDV $(B=0.357, P<0.01)$ and PDI $(B=0.221, P<0.01)$ are significantly predicting clan culture, while MSI $(B=0.046, P>0.05)$ is not significant predictor of clan culture. A value of R-square of 7.9 percent implies that dimensions of $\mathrm{NC}$ are a good predictor of clan culture. Additionally, a series of correlation coefficients were also calculated between these measures. Significant correlations were only found between clan culture and IDV ( $r$ (351) $=.208, p<.001)$, as well as between clan culture and PDI $(r$ $(351)=.200, p<.001)$.

Furthermore, the results for hypothesis 2 show that REVIDV $(B=-0.082, P<0.05)$ is a significant predictor of adhocracy culture, while MSI $(B=-0.001, P>0.05)$, UAI $(B=$ $0.025, P>0.05)$ and PDI $(B=0.015, P>0.05)$ are not a significant predictor of adhocracy culture. The value of $\mathrm{R}$-square is 1.4 percent which implies that dimensions of $\mathrm{NC}$ are not a good predictor of adhocracy culture. Additionally, a series of correlations were calculated between NC and adhocracy culture. Only one significant correlation was found, which consisted of the correlation calculated between adhocracy culture and IDV $(r(351)=-.108, p<.05)$.

The results for hypothesis 3 that UAI $(B=0.377, P<0.01)$, MSI $(B=0.110, P<0.05)$ and REVIDV $(B=0.187, P<0.01)$ significantly predict market culture, while PDI $(B=0.058, P>$ $0.05)$ is not a significant predictor of hierarchy culture. The value of $\mathrm{R}$-square is 10.2 percent which implies that dimensions of NC are a good predictor of hierarchy culture. Four Pearson's correlations were also calculated between NC and hierarchy culture. All four Pearson's correlations were found to achieve statistical significance. This analysis consisted of the correlation between hierarchy culture and UAI $(r(351)=.281, p<.001)$, hierarchy culture and IDV $(r$ $(351)=.191, p<.001)$, hierarchy culture and PDI $(r$ (351) $=.133, p<.05)$, and between hierarchy culture and MSI $(r$ $(351)=.153, p<.01)$. Moreover, the results for hypothesis 4 show that REVIDV $(B=-0.345, P<0.01)$ and UAI $(B=0.864$, $P<0.01)$ are a significant predictor of market culture, while PDI $(B=0.108, P>0.05)$, MSI $(B=0.166, P>0.05)$ are not a significant predictor of market culture. The value of $\mathrm{R}$-square is 16.6 percent which implies that dimensions of NC are a good predictor of hierarchy culture. A series of four Pearson's correlations were also conducted between market culture and NC. Three significant correlations were found, which consisted of the correlation between market culture and UAI $(r(351)=.375, p<.001)$, market culture and PDI $(r(351)$ $=.117, p<.05)$, and market culture and MSI $(r(351)=.130$, $p<.05)$.

A series of regressions analysis were conducted in order to test Hypothesis-5. Specifically, this consisted of a series of regression analyses incorporating interaction effects between $\mathrm{NC}$ and size in order to determine whether company size serves as a significant moderator of the association between $\mathrm{NC}$ and OC. The first series of analyses, focusing on clan culture and the interaction between OC and size was found to achieve statistical significance in the regressions conducted on IDV and PDI, indicating significant moderation with regard to company size in these two cases. Next, analysis focuses upon the moderational analyses conducted on adhocracy culture. None of the four interaction effects were found to achieve statistical significance in this set of analyses. This indicates no significant moderating role of company size with regard to adhocracy culture.

A series of moderational analyses were conducted focusing upon hierarchy culture. Only one significant interaction effect was found, which consisted of the interaction between IDV and company size. This indicates 
significant moderation of company size with regard to the association between IDV and hierarchy culture.

Another set of regression analyses focused on the moderational effect of company size with regard to market culture. A significant interaction effect was found in the cases of UAI and IDV, indicating significant moderation with regard to these two measures.

Further regression analyses were conducted in order to test Hypothesis-6. The first set of regression analyses focused upon whether education and position serve as substantial controls with regard to the association between NC and clan culture. While education was not found to be a significant control in any of the four analyses, position was found to be significant in all four, indicating that this measure was a substantial control with regard to clan culture.

Regression analysis was done to investigate adhocracy culture. Again, education was not found to achieve significance in any of the four analyses, while position was found to achieve significance in all four analyses. This indicates that position serves as a substantial control with regard to adhocracy culture.

Regression analysis was done to investigate hierarchy culture. The results of these analyses did not find education to be significant in any analysis. However, position was found to achieve significance with regard to the analysis conducted on IDV. This indicates that position was a substantial control with regard to hierarchy culture, though only with regard to IDV.

An additional series of regressions were conducted focusing upon market culture. Both education and position were found to achieve statistical significance in all four regression analyses, indicating that these two measures were substantial controls with regard to market culture.

\section{DISCUSSION AND CONCLUSION}

The study tested the impact of $\mathrm{NC}$ on organizational culture in the private sector of Iran. For NC four dimensions were taken into consideration i.e. uncertainty avoidance, individualism versus collectivism, power distance and masculinity versus femininity, while for organizational culture, clan culture, adhocracy culture, hierarchy culture and market culture. Hypotheses were tested using four dimensions of $\mathrm{NC}$ as independent variables and dimensions of organizational culture as dependent variables.

Results revealed that some of the dimensions of NC are insignificantly related to the dimensions of organizational culture, though the correlations conducted provided some additional support of the association between these two constructs. In case of clan culture, individualism versus collectivism and power distance showed significant relationship, while for the rest of the two dimensions relation was not significant. Furthermore, all the domains of NC showed insignificant relationship with adhocracy culture. In the case of hierarchy culture, only uncertainty avoidance, individualism and masculinity versus femininity has significant relationship, while in the case of market culture only uncertainty avoidance has significant relationship. As highlighted in the results, in the case of Iran, some of the NC indicators were loosely bounded with the organizational culture dimensions.

Additionally, the regressions conducted for Hypothesis-5 indicated significant moderation with regard to company size, though the extent of the moderation varied substantially depending upon the type of Organizational Culture in question. Overall, these results do suggest that company size can serve as an important and significant moderator of the association between NC and Organizational Culture within these data. The further series of regression analyses conducted testing Hypothesis 6 found both education and position serve as significant controls of the association between NC and Organizational Culture, however, these effects also varied substantially depending upon the Organizational Culture in question. Furthermore, position was more commonly found to be a significant control as compared with education.

Due to strict cultural norms in Iran, organizations tend to restrict many cultural improvement opportunities and the resources necessary to initiate national cultural collaboration efforts with organizational culture. In the social context, the support of government is essential for organizations to adopt cultures which help in the development of international standards and norms for better development opportunities. It seems that the dimension of power distance in Hofstede's model for Iranian culture lies in the middle of two extremes and can help organizations to improve organizational culture. This may be the reason why only the hypothesis concerning a relation of power distance with clan culture was accepted, while all the other three were rejected. These findings are in contrast with [12] findings in the US and other developing countries, where power distance and individualism are negatively correlated, meaning where there is high power distance, individualism is low and where power distance is low, individualism is high. Moreover, the relationship of NC with clan culture highlights that leadership in Iranian organizations is more supportive and managers act as mentors in organizational matters.

All the dimensions of NC have insignificant relationships with adhocracy culture. In adhocracy culture, leaders are creative and are risk takers, where subordinates follow them and only take developmental initiatives. In the case of Iran all the dimensions of NC have insignificant relationships with adhocracy culture which implies that organizational culture in Iran does not permit leaders to take risks. The major reason may be the international pressure including restrictions on joint venture. As highlighted by [12] that masculinity or femininity characteristics cannot be bound with gender, it depends on the situation where both genders can adopt either characteristic. In the case of Iran, it seems that masculine or feminine characteristics were not much influenced by adhocracy culture. Similarly, leaders with innovation capabilities fail to induce characteristics of uncertainty avoidance among the members of their organizations.

However in the case of hierarchical culture leaders promote a formalized and structured work environment and in such cultures leaders were considered as good coordinators and organizers as well. A significant positive relationship of hierarchy culture with uncertainty avoidance reveals that leaders in Iran focus on formalised organizational structures have the capability to take risks and avoid 
ambiguity to promote team work among employees. The power distance has an insignificant relationship with hierarchical culture. Therefore, it can be concluded in the case of Iran where masculinity is low as well as power distance.

Market culture as highlighted by [1] is characterised as being very customer orientated where leaders are tough, demanding and focused on achievement. All the dimensions of NC have insignificant relationships with market culture except uncertainty avoidance. The results of this study cannot be generalized to other developing countries since Iran is facing strict restrictions from international competitors. Future research should consider the size of organizations and the literature reveals that size of the firms has an impact on the culture of organizations. Since NC mostly deals with human emotion and behaviour patterns, the size of firms has a significant influence. Similarly, it is proposed that there is a need for longitudinal research in order to test the relationship between $\mathrm{NC}$ and organizational culture.

\section{ACKNOWLEDGMENT}

A. Nazarian thanks Prof. Irani and Dr Ali who not only served as my supervisors but also encouraged and challenged me throughout my academic program and this paper could not have been written without their valuable contributions.

\section{REFERENCES}

[1] K. S. Cameron and R. E. Quinn, Diagnosing and Changing Organizational culture, 3rd ed. San Francisco: Jossey-Bass, 2011.

[2] L. Sagiv and S. H. Schwartz, "Cultural values in organisations: Insights for Europe,” European Journal of International Management, vol. 1, pp. 176-190, 2007.

[3] G. Hofstede, Cultures \& organizations: Software of the mind: Intercultural cooperation and its importance for survival, New York: McGraw-Hill, pp. 4, 1991.

[4] R. Williams, Keywords: a Vocabulary of culture and Society, London: Fontana, pp. 87, 1988.

[5] C. Geertz, The Interpretation of Cultures: Selected Essays, New York: Basic Books, 1973, pp. 89.

[6] G. Hofstede, Culture's Consequences: Comparing Values, Behaviours, Institutions and Organisations across Nations, London: Sage, pp. 9, 2001.

[7] G. Hofstede, "Asian management in the 21st century," Asia Pacific Journal of Management, vol. 24, pp. 411-420, May 2007.

[8] G. Hofstede, Uncommon sense about organizations: Cases, studies and field observations, Thousand Oaks, CA: Sage, 1994 .

[9] E. H. Schein, Organisational culture and leadership, 4th ed. San Francisco: Jossey-Bass, 2010.

[10] G. Morgan, Images of Organisation (the Executive Edition), London: Sage, ch. 3, 1998.

[11] M. Alvesson, "Organizational Culture: Meaning, Discourse, and Identity," Handbook of organizational culture and climate, N. M. Ashkanasy, C. P. M. Wilderom and M. F. Peterson, Ed. Thousand Oaks, CA: Sage, ch. 2, pp. 11-27, 2010.

[12] G. Hofstede, G. J. Hofstede and M. Minkov, Cultures and Organisations: Software of the Mind. NY: McGraw Hill, 2010.

[13] P. T. Van den Berg and C. P. M. Wilderson, "Defining Measuring and Comparing Organisational Cultures," Applied Psychology: An International Review, vol. 53, no. 4, pp. 570-582, 2004.

[14] L. Smircich, "Concepts of culture and Organisational analysis," Administrative Science Quarterly, vol. 28, pp. 339-359, 1983.

[15] J. Martin and P. Frost, "The organisational culture was games: a struggle for intellectual dominance," Sociology of Organisations: structure and relationship, M. Godwyn and J. H. Gittle, Ed. Thousands Oks, CA: Sage, 2012, ch. 30, pp. 315-336.

[16] J. A. Martin and C. Siehl, "Organisational culture and counterculture: an uneasy symbiosis," Organisational dynamics, vol. 12, no. 2, pp. 52-64, Autumn1983.
[17] M. Tayeb, "Cultural determinants of organisational response to environmental demands: an empirical study in Iran," M.Litt dissertation, Dept. Humanity, Eng. University of Oxford., UK, 1979.

[18] A. J. Ali and M. Amirshahi, "The Iranian manager: work values and orientation," Journal of Business Ethic, vol. 40, pp. 133-143, October 2002

[19] M. Javidan and A. Dastmalchian, "Culture and leadership in Iran: the land of individual achievers, strong family ties, and powerful elite," Academy of Management Executive, vol. 17, no. 4, pp. 127-142, November 2003.

[20] H. Yeganeh and Z. Su, "Comprehending core cultural orientations of Iranian managers," Cross Cultural Management: An International Journal, vol. 14, no. 4, pp. 336-353, October, 2007.

[21] E. Soltani and A. Wilkinson, "The Razor's edge: managing MNC affiliates in Iran," Journal of World Business, vol. 46, no. 4, pp. 462-45, 2011.

[22] P. Namazie, "Factors Affecting the Transferability of HRM Practices in Joint Ventures," Career Development International, vol. 8, no. 7, pp. 357-366, 2003.

[23] M. Sadri and A. Sadri, "Three faces of dissent: cognitive, expressive and traditionalist discourses of discontent in contemporary Iran" Iran in the 21st century, H. Katouzian and H. Shahidi, Ed. London: Rutledge, 2008, ch. 5, pp. 63-85.

[24] H. Zareei-Matin, "Developing a model of organisational culture based on the Islamic values and evaluating its effect on job satisfaction," Ph.D. dissertation, Dept. Mang. Persian., Tarbiat Modarres University, Tehran, Iran, 1995

[25] M. Sadeghi, "Studying the effect of organisational culture on job satisfaction," Ph.D. dissertation, Dept. Mang. Persian., Imam Sadegh University., Tehran, Iran, 1997.

[26] D. Gholamzadeh and K. Yazdanfar, "Analysis Organizational Culture level in Selected Iranian Corporations using Denison Model (Case Study: Snova, Hayer, Lorch and Mana Co.)," Interdisciplinary Journal of Contemporary research in business, vol. 3, no. 11, pp. 791-798, March 2012.

[27] M. Hashemiyan, "The effect of organisational culture on job satisfaction of organisational members in a military organisation." Ph.D. dissertation, Dept. Humanities. Persian., Tarbiat Modarres University., Tehran, Iran, 1998.

[28] H. Torabikia, "Studying the relationship between organisational culture and job satisfaction," MA dissertation, Dept. Mang. Persian, Shahid Beheshti University., Tehran. Iran, 1998.

[29] S. K. Mehr, B. A. Kenari, S. Emadi, and M. S. Hosieni, "Relationship between organisational culture with effectiveness of staffs of physical education offices of Mazandran province," European Journal of Experimental Biology, vol. 2, no. 3, pp. 781-785, 2012.

[30] S. Hosseini-Safa, "A comparative study of the effect of organisational culture on management style in 7 companies," Ph.D. dissertation, Dept. Business. Persian., Shahid Beheshti University., Tehran, Iran, 1999

[31] G. Moradi, "Studying the effect of organisational culture on the selection of Management style by public sector managers in Ilam province," Ph.D. dissertation, Dept. Business. Persian, Azad University., Kerman, Iran, 1998

[32] F. Tojari, M. S. Heris, and A. Zarei, "Structural equation modelling analysis of effect of leadership and organisational culture on effectiveness in sport organisations," African Journal of Business Management, vol. 5, no. 21, pp. 8634-8641, 2011 .

[33] U. Sekaran, "Methodological and Theoretical issues and Advancements in Cross-Cultural Research," Journal of International Business Studies, vol. 14, no. 2, pp. 61-73, 1983.

[34] P. W. Dorfman and J. P. Howell, "Dimensions of National Culture and Effective Leadership Patterns: Hofstede revisited," Advances in International Comparative Management, vol. 3, pp. 127-150, 1988

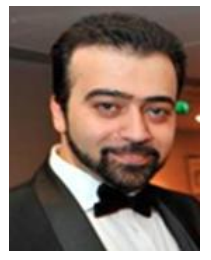

Alireza Nazarian was born in Tehran, Iran in 1977. He finished his BSc in Industrial Engineering from University of Science and Technology in Babol, Iran. He moved to UK in 2002 and graduated from University of Bristol in MSc in Economics, Finance and Management. Currently his is doing $\mathrm{PhD}$ in University of Brunel in London, UK in management studies. He worked as an International Marketing manager for south-eastern pars product Co in Tehran, Iran. He started his career in higher education in his capacity as a Head of Faculty in WGGS from 2005 to 2011. $\mathrm{He}$ also worked in University of Westminster as a Visiting Lecturer from 2008 till 2010. Mr Nazarian is a member of BAM (British Academy of Management) since 2011. 